\title{
Gastrointestinal Pain, CTCAE
}

National Cancer Institute

\section{Source}

National Cancer Institute. Gastrointestinal Pain, CT CAE. NCI Thesaurus. Code C143510.

A disorder characterized by a sensation of marked discomfort in the gastrointestinal region. 